\title{
COMPARISON OF PARAMETERS OF SURFACE INTEGRITY OF MACHINED DUPLEX AND AUSTENITE STAINLESS STEELS IN RELATION TO TOOL GEOMETRY
}

\author{
JiŘí ČAPeK ${ }^{a, *}, Z_{\text {DenĚK Pitrmuc }}^{b}$, KAmil KolaříK $^{a}$, Libor BeráneK $^{b}$, \\ NikOLAJ GANEV ${ }^{a}$ \\ a Department of Solid State Engineering, Faculty of Nuclear Sciences and Physical Engineering, Czech Technical \\ University in Prague \\ ${ }^{b}$ Department of Machining, Process Planning and Metrology, Faculty of Mechanical Engineering, Czech \\ Technical University in Prague \\ * corresponding author: capekjir@fjfi.cvut.cz
}

\begin{abstract}
The goal of this contribution was to describe parameters of surface integrity of two machined materials; austenite and duplex stainless steel. Residual stresses and presence of straininduced martensite were studied as a function of the side rake angle. Residual stresses of surface and sub-surface layers were determined using X-ray diffraction techniques and hole-drilling method. By using X-ray diffraction, it is possible to determine residual stresses in each phase separately, in comparison with hole-drilling method. The presence of strain-induced martensite was investigated using Barkhausen noise and optical microscope.
\end{abstract}

KEYWORDS: stainless steels, machining, X-ray diffraction, residual stresses, strain-induced martensite.

\section{INTRODUCTION}

Actual state of technology of sewage disposal plants (SDP) basically does not solve the problem of purification of fats and oils. Using mobile tricanter device substantially changes the attitude of waste processing to SDP. It removes transporting of waste from small, problematic, or dangerous environmental sources and enables using device on the polluted place. The mobile version of tricanter device poses increased requirement on reducing of energy consumption and mobility given by size and weight reducing. The mobile separation tricanter may not be discernible from mobile separation decanter device. The differences are mainly in centrifuge and accessories of device. Tricanter device enables three-phase separation with simultaneous separation of two immiscible liquids with different densities and one solid phase, provided that the solid phase is the heaviest phase using high revolution, i.e. centrifugal force. The main problems are removing of individual phases and purity observation.

Duplex and austenite steels are usually used for their properties, primarily for the high corrosion resistance. Duplex steels combine properties of both phases and moreover, due to two-phase microstructure, some properties are better than high-alloyed austenite steel, e.g. abrasion resistance [1]. Abrasion and corrosion resistance have to be one of the main required properties. Not only properties of used material but it is necessary to investigate quality of machined surface - surface integrity, too [2, 3.

Both, austenite and duplex steels have relatively low thermal conductivity (approx. $16 \mathrm{~W} / \mathrm{mK}$ ) [4] which leads to insufficient heat distribution into chip and workpiece and to excessive heat accumulation in cutting zone. This heat generation can result in microstructural changes, local changes of chemical composition, surface discoloration or inducing undesirable tensile residual stresses.

The gradient of residual stresses (RS) is more important indicator of machined material than surface RS. A situation may arise that there are the favorable compressive RS on the surface but with a steep RS gradient which can result in very high unfavorable tensile RS in the sub-surface layers, and vice versa [5]. For this reason, it is very important to investigate the RS gradient.

Analysis of polycrystalline materials by X-ray diffraction methods is suitable for gaining information about state of RS of both the surface and subsurface layers. On the other hand, the other methods as hole-drilling determine the RS gradient from total relieved deformation of material after disruption of RS balance.

The strain-induced martensite can be caused by sufficiently high rate of plastic deformation of surface layers and also by temperature instability of austenite [6. 7]. Martensite is harder and more brittle in comparison with austenite steels and thus changes their properties. For strain-induced martensite determination, e.g. the optical microscopy or Barkhausen noise analysis can be used.

\section{THEORY}

Duplex stainless steels have high corrosion resistance in many environments, where the standard austenite steel is consumed, and where its properties sig- 
nificantly exceed austenite steel. Thereby, smaller amount of material from duplex steel is necessary to manufacture function components. Austenite and duplex steels are susceptible to mechanical reinforcement, i.e. local changes in mechanical properties of surface layers. Local changes, e.g. hardness, can lead to tools vibration during machining of the final component, which results in additional material inhomogeneity and blunting tool 8 .

Realizing that austenite steel has face centred cubic ( fcc) lattice with close-packing structure of atoms, the primary slip system goes along $\{111\}\langle 110\rangle$ The number of slip systems is 12 , which is the sufficient amount to plastic deformation. Moving dislocations form so called stair-rod dislocations which have small stacking fault energy, i.e. high energy is necessary to have for intersect or cross slip of these dislocations 9 . Therefore, the austenite steels are prone to workhardening, which cause mechanical modification and inhomogeneity on the machined surface, and leads to e.g. unstable chip formation. The second type of deformation of high alloyed austenite steel takes place via twins. On the contrary, the ferrite crystallizes in a body centered cubic lattice $(b c c)$. The direction slip in $b c c$ materials is always $\langle 111\rangle$. Since in the $b c c$ lattice is not close-packing structure of atoms, more slip planes assert during the deformation, mostly planes $\{110\}$ and $\{211\}$.

In engineering practice, the residual stresses are often determined on the basis of total sample deformation (e.g. hole-drilling method). This procedure considers the solid state as a compact continuous body, and therefore could not take into account degradation processes which rise separately into each phase components. Using X-ray diffraction (XRD) method, the residual stresses can be determined into both the phases separately [10].

For strain-induced martensite determination, several method can be used. X-ray diffraction and Barkhausen noise belong to non-destructive techniques and e.g. microhardness measurements or optical microscopy to destructive analysis.

\section{EXPERIMENT}

The tested samples of tube shape of $100 / 86 \mathrm{~mm}$ in diameter were made of AISI 304 (austenite) and AISI 2205 (duplex) type of stainless steel. The samples were annealed in air laboratory furnace for 5 hours at $420{ }^{\circ} \mathrm{C}$ in order to reduce bulk macroscopic residual stresses.

For machining of the surfaces, four types of side rake angle were used $\left(-6^{\circ} ;-2^{\circ} ;+7^{\circ}\right.$ and $\left.+12^{\circ}\right)$. Side rake angles are considered in combination with particular insert holder, which has negative rake angle $\left(-6^{\circ}\right)$. DCLNR/L R-clamp tool-holders with lead angle of $95^{\circ}$ ( side cutting edge angle $-5^{\circ}$ ) for four $80^{\circ}$ negative rhombic inserts were used, namely F3M, SF, NF, and PP chip breakers of Iscar Cutting Tools. All inserts had the same tip radius $0.4 \mathrm{~mm}$. For elimination of blunting tool effect, the cutting tool was always new for machining of each tube segment.

The surface of the austenite sample was machined with different tool's feed, $f=0.1,0.15 ; 0.2$ and $0.31 \mathrm{~mm} / \mathrm{rev}$, using constant value of cutting depth $0.5 \mathrm{~mm}$ and cutting speed $155 \mathrm{~m} / \mathrm{min}$. The second series of machined samples were set up the cutting conditions of experiment using different tool geometry: feed rate $0.14 \mathrm{~mm} / \mathrm{rev}$, cutting speed $140 \mathrm{~m} / \mathrm{min}$, and depth of cut $2 \mathrm{~mm}$. Direction of feed rate was parallel to axis of the sample (tube) $A$ and perpendicular to tangential direction $T$. According to the principles of design of experiments (DOE) method, three $1 \mathrm{~cm}$ tube segments were machined using the same cutting conditions.

Using $\mathrm{Mn} K \alpha$ and $\mathrm{Cr} K \alpha$ radiation, $X$ 'Pert $P R O$ $M P D$ diffractometer was used to measure lattice deformations in austenite and ferrite, respectively. The average penetration depth of $\mathrm{X}$-ray radiation is approx. $4 \mu \mathrm{m}$ and $6 \mu \mathrm{m}$ for ferrite and austenite phase, respectively. Diffraction angles $2 \theta^{h k l}$ were determined from the peaks of the diffraction lines $K \alpha_{1}$ of planes $\{311\}$ and $\{211\}$ of austenite and ferrite, respectively. Diffraction lines $K \alpha_{1}$ were fitted by Pearson VII function and Rachinger's method was used for separation of the diffraction lines $K \alpha_{1}$ and $K \alpha_{2}$. For residual stress determination, Winholtz \& Cohen method [11] and X-ray elastic constants $1 / 2 s_{2}=7.18 \mathrm{TPa}^{-1}, s_{1}=-1.20 \mathrm{TPa}^{-1}$ and $1 / 2 s_{2}=5.75 \mathrm{TPa}^{-1}, s_{1}=-1.25 \mathrm{TPa}^{-1}$ were used for austenite and ferrite phase, respectively. In order to analyze the stress gradients beneath the samples surface, layers of material were gradually removed by electro-chemical polishing in the center of the sample.

Hole-drilling method was performed using sintered carbide milling drill of $1.8 \mathrm{~mm}$ in diameter and the holes had depth of $2 \mathrm{~mm}$. The detection of released deformations was done by 3 rectangular tensometric rosettes. The stresses were calculating using macroscopic elastic constants: Young modulus $200 \mathrm{GPa}$ and Poisson ratio 0.3.

The measurements of Barkhausen noise were performed using a commercial unit Stresstech Rollscan 350 magneto-elastic analyser with a standard sensor. Main parameters of the applied method were: sinusoidal shape of magnetic signal, magnetic voltage $3.5 \mathrm{~V}$, and frequency $75 \mathrm{~Hz}$. In practice typical expectable penetration depth in this experimental arrangement is in the range of $20 \mu \mathrm{m}$, but generally depend on frequency and the analysed material.

For obtaining optical microscopy images, the radial cut of each sample was made. The electrolytic etching with $10 \%$ Oxalic acid of investigated surfaces was employed. The images were achieved by inclined illumination with $250 \times$ magnification. 

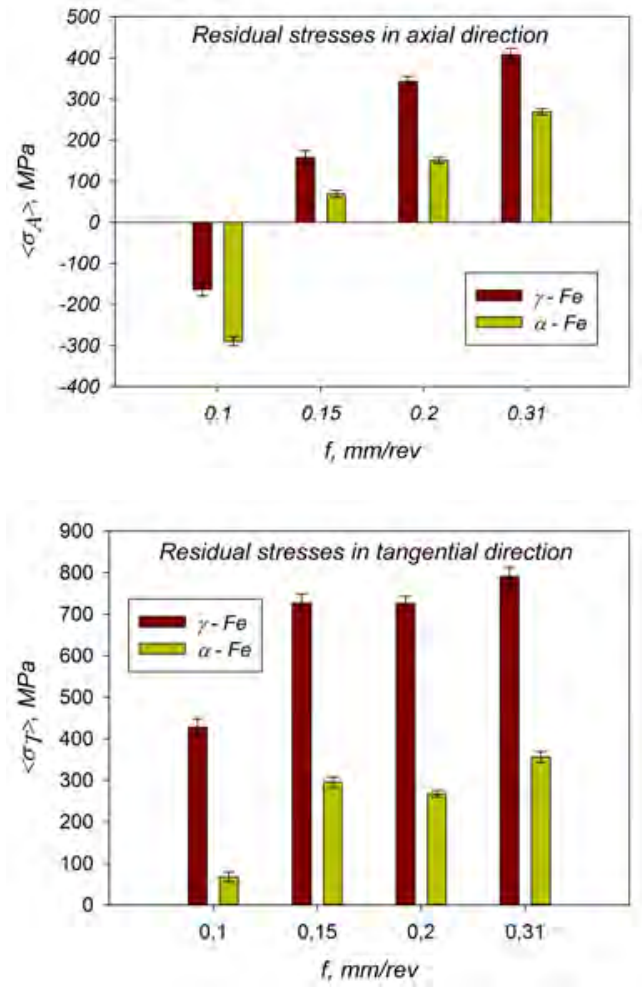

FigURE 1. Averaged values of residual stresses $\left\langle\sigma_{A}\right\rangle, \mathrm{MPa}$ (top) and $\left\langle\sigma_{T}\right\rangle, \mathrm{MPa}$ (bottom) of both phases depending on tool's feed $f, \mathrm{~mm} / \mathrm{rev}$.

\section{Results And Discussions}

\subsection{Dependence on tool's feed $f$}

In Figs. 1, there are dependence of residual stresses values of ferritic and austenitic phases on the tool's feed. The dependence of residual stresses $\langle\sigma\rangle$ on the tool's feed $f$ is increasing, see Figs. 11. This trend is identical in the both analyzed directions; axial and tangential. It can be concluded that using a smaller tool's feed leads to lower values of residual stresses. This effect is related to "an amount of chip". Higher tool's feed, cutting depth and cutting speed lead to higher cutting force and higher heat generation. If the heat effect is dominant, the tensile stresses are generated. Generally, the temperature influence causes the tensile RS and contrarily, the plastic deformation leads to compressive RS. The type of the RS and their value deeply depend on the mechanical and thermal properties of the machined material [5, 12.

\subsection{Dependence on the Side RAKe Angle}

\subsubsection{Surface Residual Stresses}

In Figs. 2 there are influences of surface macroscopic residual stresses $\left\langle\sigma_{A}\right\rangle,\left\langle\sigma_{T}\right\rangle, \mathrm{MPa}$ on the side rake angle, ${ }^{\circ}$. These residual stresses were averaged from three values of RS of tube segments machined using same side rake angle.

Generally, the increasing of the side rake angle in the positive direction leads to a lowering of cutting force and temperature in the cutting zone [5]. For prediction of RS dependence on the side rake angle, the yield strength ratio $\mathrm{Rm} / \mathrm{Rp}_{0.2}$ of the given material is necessary to take into account.

For austenite steel, the yield strength ratio is approx. 2.5, which is typical value for plastic material. The tensile RS are created during machining using great load on the cutting tool, i.e. using the negative side rake angle, and smaller load causes the compressive RS, i.e. using the positive side rake angle [5]. For this reason, higher compressive (axial direction) and smaller tensile (tangential direction) RS were determined with increasing of the side rake angle, see Fig. $2 \mathrm{a}$

On the other hand, for ferrite steel, the yield strength ratio is less than 1.25 , which is typical value for elastic materials. According to [5], the shear type chips should be created which should cause the interruption of the connection between chips and the material. The additional effect of strain filed of chips is not transferred in the machined surface. For this reason, the greater force causes that the plastic deformation influence is predominant and higher compressive or smaller tensile RS may be determined with increasing of the side rake angle.

Furthermore, for duplex steel, which consists of both phases, it is possible to presume that the dependence of RS on the side rake angle is generally not monotonic for both the phases because of their mutual influence during plastic deformation, see Figs. 2b, 2c

\subsubsection{RESIDUAL STRESSES GRADIENT}

The RS gradients depending on the side rake angles were determined, see Figs. 3 As can be seen in Figs. 3a, 3b, the RS gradients are without any dependence on the side rake angle in the case of austenite steel. On the contrary, for duplex steel, there are clearly differences of the RS values depending on side rake angle in both austenite and ferrite phase.

The reason resides in two phase material and mutual influence of both phases during plastic deformation. In the case of one phase steel, the difference of plastic deformation power is not so significant to change the state of RS in the sub-surface layers using the different side rake angle, see Figs. 3a, 3b. On the contrary, for two phase steel, the differences of RS are evident, see Figs. 3c, 3d With the increasing side rake angles, the maximum stress position is moved deeper into the material which is in line with results in [13].

In Figs. 4 there is a comparison of RS gradients determined by XRD and hole-drilling method. Mostly, the macroscopic RS of bulk material can be estimated as approx. zero, see austenite steel in Figs 3a, 3b Nevertheless, the compressive RS of ferrite and the tensile RS of austenite phase of bulk are seen in Figs. $3 \mathrm{c} 3 \mathrm{~d}$. By XRD, the determination of the RS is possible in each phase, separately. Because of the similar mass ratio of ferrite and austenite phase in the duplex steel, the RS of bulk can be approximately predicted by value $\sigma_{\text {bulk }} \approx\left(\sigma_{\text {ferrite }}+\right.$ Gaustenite $) / 2$. However, 


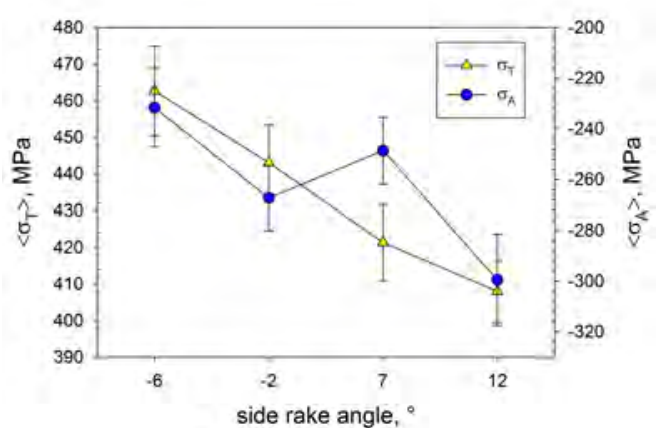

(A) . Austenite steel.

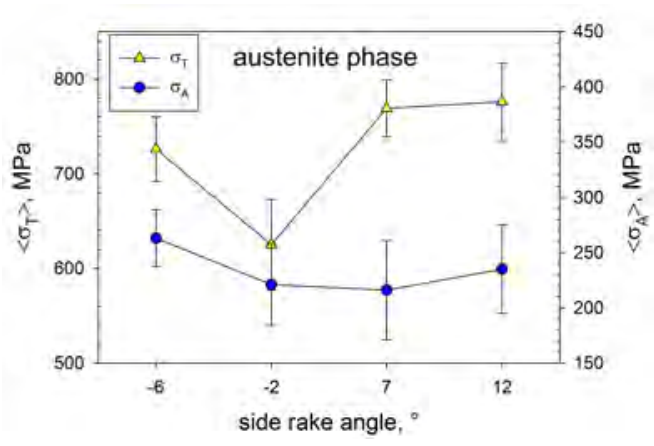

(в). Duplex steel - austenite phase.

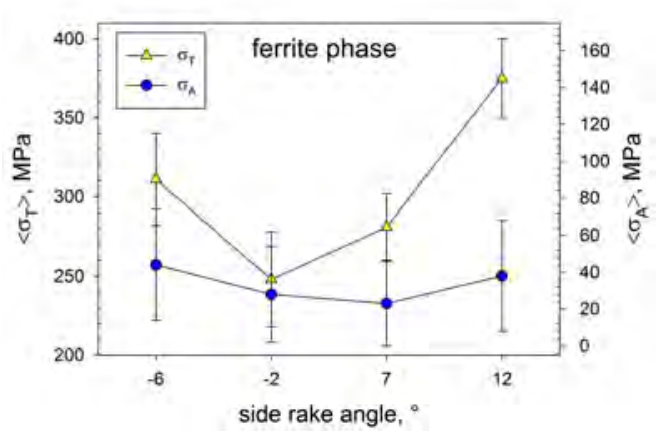

(c) . Duplex steel - ferrite phase.

Figure 2. Axial and tangential residual stresses $\left\langle\sigma_{A}\right\rangle,\left\langle\sigma_{T}\right\rangle, \mathrm{MPa}$ on the side rake angle, ${ }^{\circ}$.

the hole-drilling method is based on deformation of the measured material as the whole. It is evident from Fig. 4 that $\sigma_{\text {bulk }} \approx \sigma_{\text {hole-drill }} \approx 0$ which is in line with expectation [10. Moreover, the continuity of both methods of RS determination was verified.

\subsubsection{STRAIN-INDUCED MARTENSITE DETERMINATION}

In Fig. 5, there are the optical microscopy images of the radial cut for two types of chip breakers, for maximum negative (F3M chip breaker, i.e. side rake angle $-6^{\circ}$ ) and maximally positive (SF chip breaker, i.e. side rake angle $+12^{\circ}$ ).

From theory follows that the primary shear zone is decreasing with increasing positive side rake angle. In other words, increasing side rake angle results in lower cutting force and temperature [14. Due to

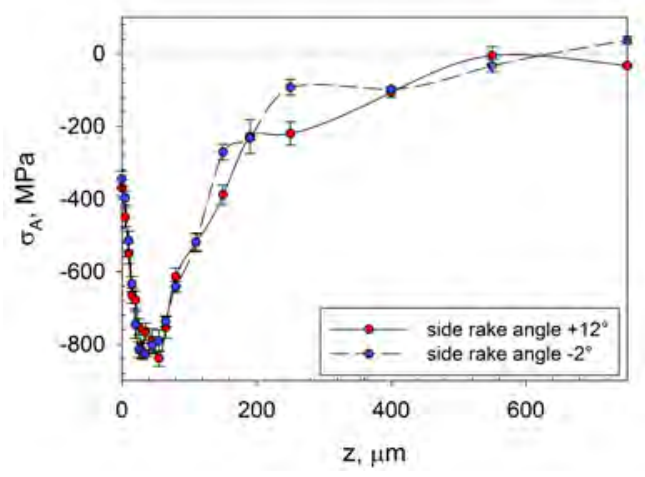

(A) . Austenite steel - axial direction.

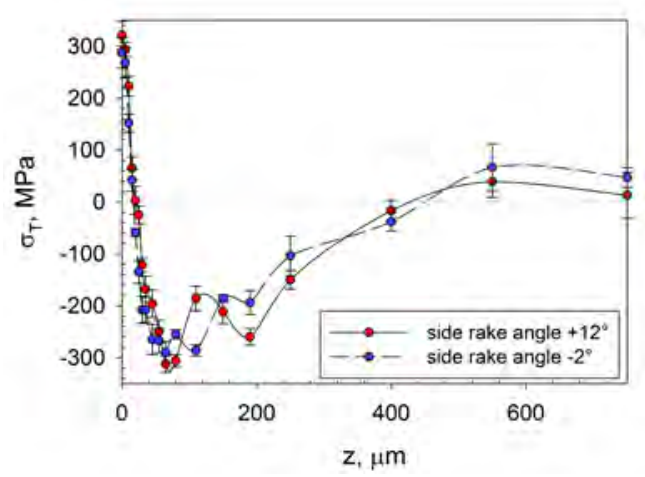

(B) . Austenite steel - tangential direction.

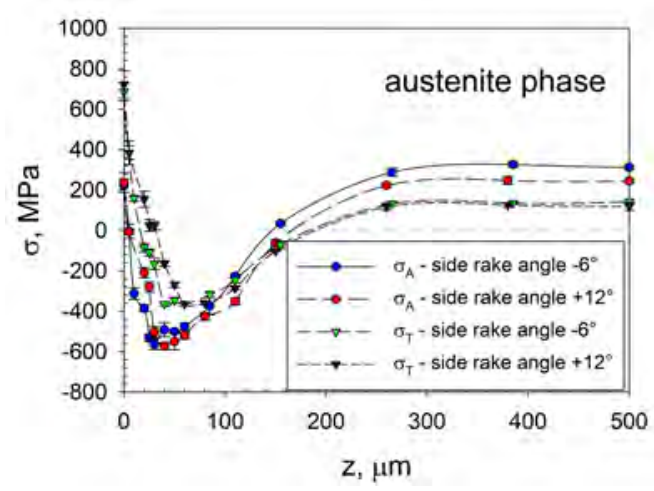

(C) . Duplex steel — austenite phase.

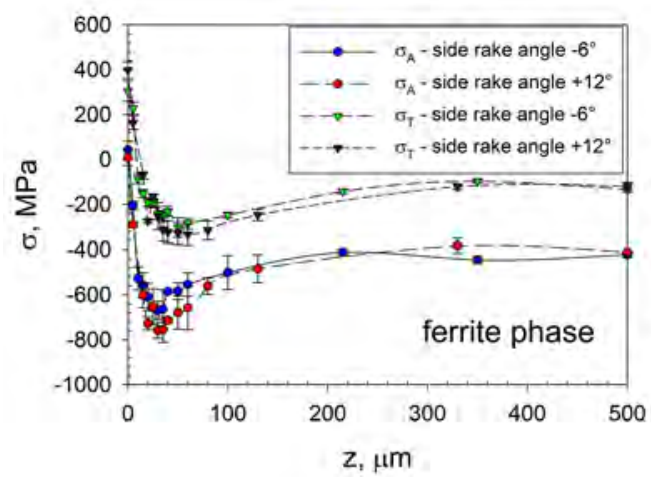

(D) . Duplex steel — ferrite phase.

Figure 3. Residual stress gradients $\sigma_{A}, \sigma_{T}$ using side rake angles $-6^{\circ},-2^{\circ}$ and $+12^{\circ}$. 


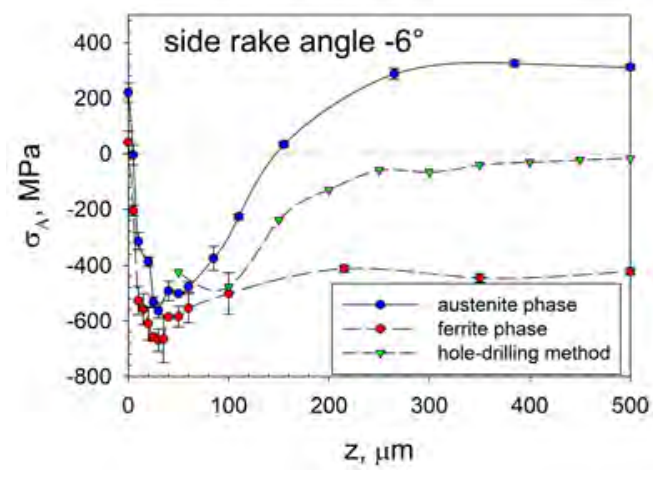

(A) Axial direction; side rake angle $-6^{\circ}$.

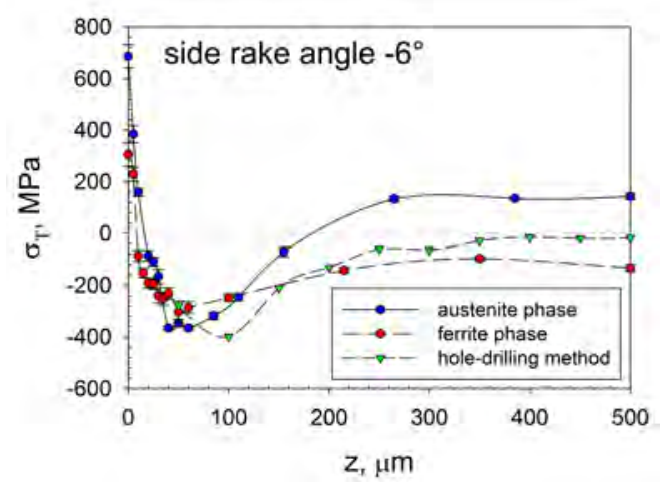

(B) . Tangential direction; side rake angle $-6^{\circ}$.

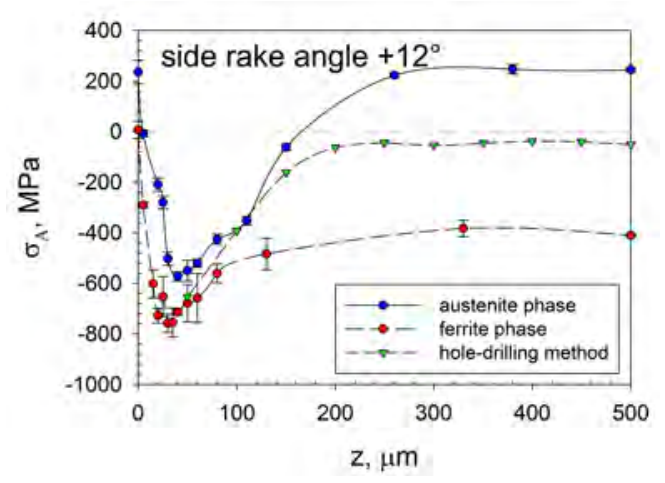

(c) . Axial direction; side rake angle $+12^{\circ}$.

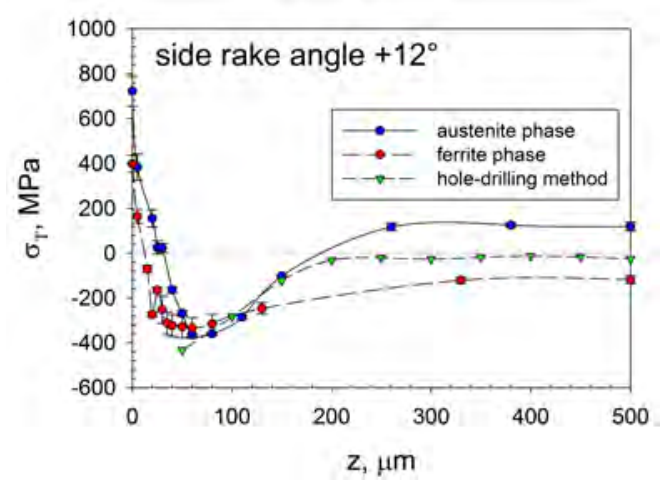

(D) . Tangential direction; side rake angle $+12^{\circ}$.

Figure 4. Residual stress gradients $\sigma_{A}, \sigma_{T}$ determined by XRD and hole-drilling method. lower cutting force, the primary shear zone tends to get wider and the plastically affected surface layers is thinner.

In Figs. 5a and 5b there is evident the possibility presence of strain-induced martensite. For confirmation of this statement, other analysis is necessary to do, e.g. Barkhausen noise analysis, see Fig. 6. After confirmation of presence of strain-induced martensite, it is evident that there are differences between thickness of surface layer with strain-induced martensite, see Figs. 5a and 5b. Increasing positive side rake angle, the thickness of mentioned layer is decreasing which is in line with presented theory.

In the case of duplex steel, see Figs. $5 \mathrm{c}$ and $5 \mathrm{~d}$, it is possible to observe differences in amount of straininduced martensite, i.e. dark blue grains. With increasing positive side rake angle, the amount of straininduced martensite decreases. Using higher positive side rake angle, the cutting tool causes lower plastic deformation and therefore, the lower amount of straininduced martensite is created. The thickness of layer containing strain-induced martensite is approximately identical.

In Fig. 6, there is a comparison of Barkhausen noise records of machined surface with and without straininduced martensite of austenite steel. The presence of ferromagnetic phase in paramagnetic austenite, i. e. strain-induced martensite, was absolutely confirmed by Barkhausen noise. The Barkhausen noise record of non-machined surface has constant value, i. e. equal to signal creating by measuring probe. The confirmation of the presence of strain-induced martensite in the duplex steel is more complicated due to presence ferromagnetic ferritic phase. The higher value of magneto-elastic parameters are not only due to higher ratio of ferromagnetic phase but also due to residual stresses, dislocation density, grain-boundaries etc.

\section{Conclusions}

The present study showed:

- Regarding dynamical loading of the final product, it is necessary to have a suitable state of residual stresses in the surface layers, i.e. high value of compressive stresses. For this reason, lower tool's feed is more preferable when the final product is manufactured. With respect to our results, see Figs. 1. and recommendation of tools producer, the value of tool's feed $0.14 \mathrm{~mm} / \mathrm{rev}$ was selected.

- The surface RS distribution is dependent not only on the side rake angle but on the material, too. For austenite (one phase steel), the dependence of RS on the side rake angle is decreasing. On the contrary, for austenite and ferrite (in the two phase steel), the dependence is not monotonous. The reason is yield strength ratio which is different for austenite and ferrite.

- The RS gradients are without any dependence on the side rake angle in the case of austenite steel. 


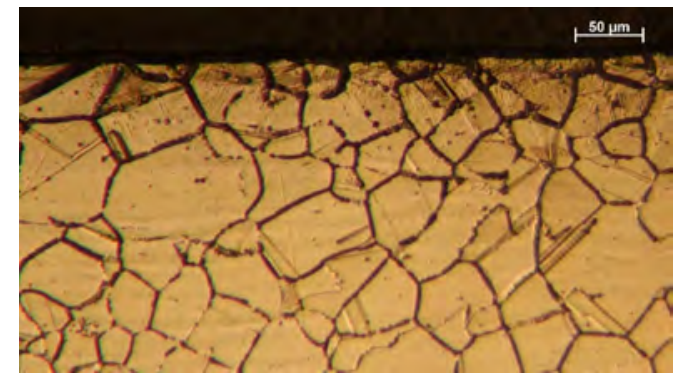

(A) . Austenite steel machined by F3M chip breaker, i.e. side rake angle $-6^{\circ}$.

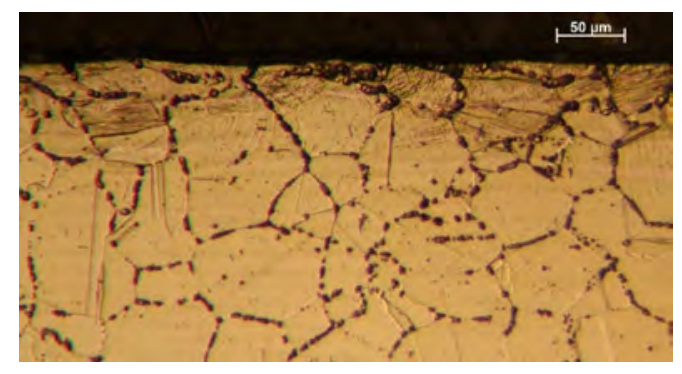

(в) . Austenite steel machined by SF chip breaker, i.e. side rake angle $+12^{\circ}$.

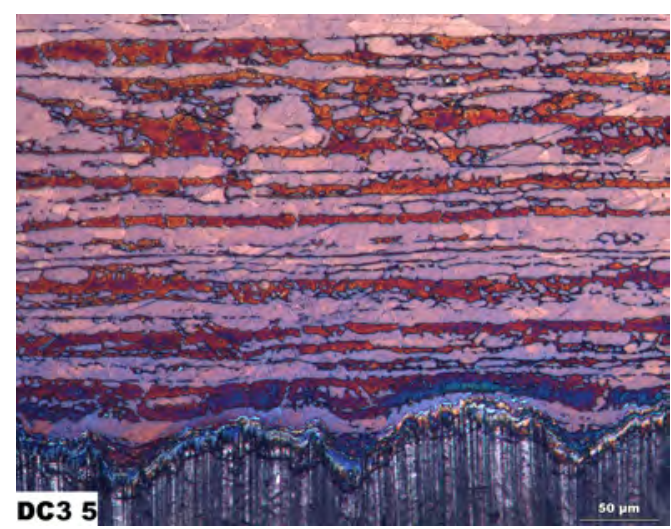

(C) . Duplex steel machined by F3M chip breaker, i.e. side rake angle $-6^{\circ}$.

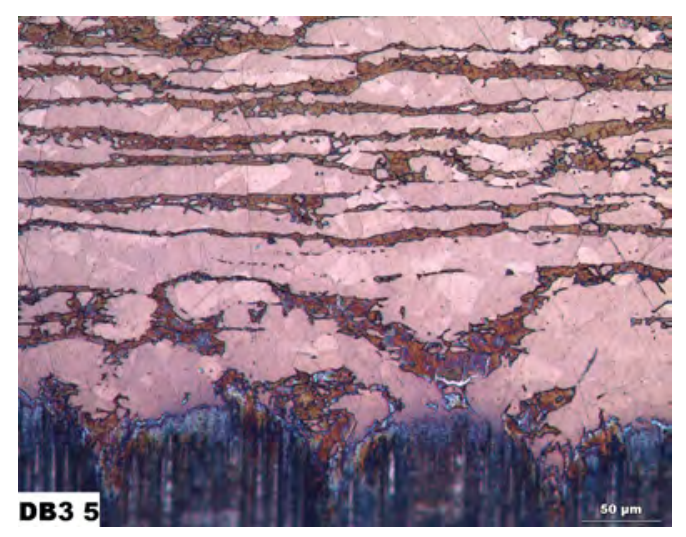

(D) . Duplex steel machined by SF chip breaker, i.e. side rake angle $+12^{\circ}$.

FiguRE 5. Optical microscopy images of the radial cut of four samples; magnification $250 \times$, electrolytic etching $10 \%$ oxalic acid.

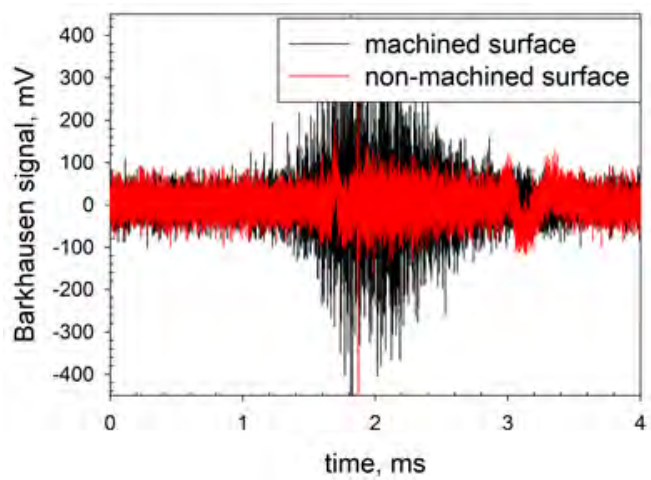

FiguRE 6. Barkhausen noise records of austenite steel of machined surface with and non-machined surface without strain-induced martensite.

On the contrary, for duplex steel, there are clearly differences in RS values depending on side rake angle in both austenite and ferrite phase. The reason is mutual influence of the both phases during plastic deformation.

- For the similar mass ratio of ferrite and austenite in the duplex steel, the RS determined by hole-drilling method are approx. the average between the RS determined by XRD of ferrite and austenite phase, separately.

- Moreover, the RS of austenite phase are generally more tensile in comparison with the RS of ferrite phase; see Figs. 4, which is in correlation with [5].

- In Figs. 5a and 5b there is not evident difference between twins and strain-induced martensite. For confirmation of strain-induced martensite presence in the austenite steel, the Barkhausen noise analysis was used, see Fig. 6.

- It follows from Figs. 5 that with increasing positive side rake angle, the amount of strain-induced martensite and the layer containing strain-induced martensite is decreasing for duplex and austenite steel, respectively.

- Due to correlation between amount of straininduced martensite and microhardness, it is possible to presume the dependence of microhardness on side rake angle.

\section{ACKNOWLEDGEMENTS}

J. Capek acknowledges support of the Grant Agency of the Czech Technical University in Prague, grant No. SGS16/245/OHK4/3T/14. Others were supported by TA04020658, the Technology Agency of the Czech Republic.

\section{REFERENCES}

[1] R. Dakhlaoui, et al. Mechanical properties of phases in austeno-ferritic duplex stainless steel-surface stresses studied by x-ray diffraction. Mater Sci Eng: A 444(1):6-17, 2007.

DOI:http://dx.doi.org/10.1016/j.msea.2006.06.074 
[2] D. Y. Jang, et al. Surface residual stresses in machined austenitic stainless steel. Wear 194(1):168-173, 1996. DOI:10.1016/0043-1648(95)06838-4

[3] R. MŠsaoubi, et al. Residual stress analysis in orthogonal machining of standard and resulfurized aisi 3161 steels. J Mater Process Technol 96(1):225-233, 1999. DOI:http://dx.doi.org/10.1016/S0924-0136(99)00359-3

[4] A. Boniardi, et al. Stainless steels, 2011. [2016-06-09], http://www.lucefin.com/wp-content/files_mf/ stainlesssteels_low.pdf.

[5] F. Neckář, I. Kvasnička. Vybrané statě z úběru materiálu. České vysoké učení technické, 1991.

[6] P. Haušild, K. Kolařík, M. Karlík. Characterization of strain-induced martensitic transformation in a301 stainless steel by barkhausen noise measurement. Mater Des 44:548-554, 2013. DOI:http://dx.doi.org/10.1016/j.matdes.2012.08.058

[7] H. T. Chen, M. F. Yan, S. S. Fu. Martensite transformation induced by plasma nitrocarburizing on aisi304 austenitic stainless steel. Vacuum 105:33-38, 2014.

DOI:http://dx.doi.org/10.1016/j.vacuum.2014.01.032

[8] J. Čapek, et al. Residual stress analysis into each phase of turning duplex steel and their influence on service life of rotary and dynamically loaded components. In České vysoké učení technické (ed.), The 5th Student Scientific Conference on Solid State Physics, pp. 11-15. 2005.
[9] J. J. Moverare, M. Odén. Deformation behaviour of a prestrained duplex stainless steel. Mater Sci Eng: A 337(1):25-38, 2002.

DOI:http://dx.doi.org/10.1016/S0921-5093(02)00022-9

[10] K. Kolařík, et al. Combining xrd with hole-drilling method in residual stress gradient analysis of laser hardened c45 steel. Adv Mater Res 996:277-282, 2014. DOI:10.4028/www.scientific.net/AMR.996.277

[11] U. Welzel, et al. Stress analysis of polycrystalline thin films and surface regions by x-ray diffraction. $J$ Appl Crystallogr 38(1):1-29, 2005. DOI:10.1107/S0021889804029516.

[12] T. Leppert, R. L. Peng. Residual stresses in surface layer after dry and mql turning of aisi $316 \mathrm{l}$ steel. Produc Eng 6(4-5):367-374, 2012. DOI:10.1007/s11740-012-0389-3.

[13] P. Dahlman, et al. The influence of rake angle, cutting feed and cutting depth on residual stresses in hard turning. J Mater Process Technol 147(2):181-184, 2004.

[14] H. Saglam, F. Unsacar, S. Yaldiz. Investigation of the effect of rake angle and approaching angle on main cutting force and tool tip temperature. Int J Mach Tool Manu 46(2):132-141, 2006. DOI:http://dx.doi.org/10.1016/j.ijmachtools.2005.05.002 